many other dangerous mistakes which are too technical to be named here, and although, after a short training, a native midwife may not be equal to the successful conduct of a difficult case, her management of an ordinary one will be free from all injurious and unnecessary interference, and she will have learnt to give up those violent methods of procedure which cost so many lives, and cause so much ill-health."

The important subject of training sick-nurses for private house is also referred to.

Lady Dufferin has enjoyed, what must have been to her the exquisite pleasure of seeing her philanthropic efforts fully appreciated by the men and women of India, and of receiving from all sides expressions of gratitude and praise. But it must have given even greater satisfaction to her to find that, in three short years, the scheme, which she initiated and organized, has become so firmly established, and so practically fruitful. The words which conclude this admirable paper breathe a spirit of benevolence and wisdom which cannot fail to touch the hearts and evoke the practical sympathies of those who read them:-

"The National Association, and all those who have subscribed to it-those who have worked for it-those who are now striving to teach, and to train, and to relieve the sick,-have done and are doing what they can for the women of this country; but if their work is to be a universal one,-if relief is to be brought, not to tens, but to hundreds of thousands of Indian homes, as it should be,- - then, it is not one Society, or acertain number of single individuals who can accomplish such a task. It is the determined attitude of the men of this country which must do it. It lies with them to give the women, dependent upon them, relief in suffering, to save them from a kind of professional aid which is oftentimes destruction, and to introduce into their households those sanitary regulations, and that intelligent management of women and children which save life, and promote good health."

\section{RIGOR MORTIS.}

Observatrons are needed in India regarding the period which intervenes between death and the supervention of Rigor Mortis under different circumstances, and the duration of the condition. In a notable case which was recently tried in the Calcutta High Court - of which we hope to give a full report in a future number - the question when death occurred, and the presumptions deduced from the state of the body as bearing upon that question, became of vital importance. The two points on which most stress were laid, as fixing the approximate time of death were, the degree of digestion which a meal of known composition and quantity, taken at a known time, had undergone, and the presence of Rigor Mortis when the body was examined. The question as regards the food was, how many hours would such a meal, taken at such a time, probably take to reach the stage of digestion which was revealed by post-mortem examination? And the question as regards Rigor Mortis was, how soon, under the known circumstances of health, season, and cause of death, would it probably supervene, and how long would it last? For the solution of questions such as these, the experience derived from systematic observations is indispensable, and surmises, founded on general knowledge and the facts of the particular case, are almost worthless. Observations regarding Rigor Mortis require no special training or skill, and no appliances, only accuracy and patience, and they are such as can easily be carried out by many observers working independently, - the results being subsequently collated for general inference. The points requiring special attention in such an enquiry are these :-

1. Locality.

2. Season.

3. Temperature and humidity.

4. Sex of subject.

5. Age.

6. Duration of illness.

7. Cause of death.

8. Date and hour of death.

9. Manner of death.

10. State of muscular system at time of death.

11. Temperature of body at and after death.

12. Rate and duration of cooling process.

13. Hour of earliest appearance of Rigor Mortis.

14. Groups of muscles successively stiffened. 
15. Date and hour of disappearance of Rigor Mortis.

16. Order of relaxation of different groups of muscles.

17. Time of appearance of first signs of putrefaction.

A scheme of this sort would, no doubt, require continuous and careful watching; but there is no reason why the same subject should not be watched, in turn, by different persons, if one person could not attend sufficiently often or long. Much useful information could, no doubt, be furnished by observations less systematic and complete than those which we have sketched out; but of the scientific and medico-legal value of a series of, say, one hundred observations on the plan above indicated, there can be no doubt. Here there is an opportunity for useful collective investigation. We should esteem it a pleasure to gather and compile the results of such an inquiry; and, in the event of volunteers coming forward to undertake the necessary observations, we should gladly print and distribute forms in accordance with the scheme above indicated, receive them when completed, and amalgamate the whole into a concise and convenient shape.

\section{FANCY FEES.}

The Government of India has recently ruled that "when a Medical Officer is permitted to attend a Native Prince, the fee to be paid for such attendance must be settled by Government, to whom the amount of the fee proposed should be reported by the Political Agent for sanction, before it is communicated to the Medical Officer concerued." What circumstances or considerations have led to the issue of this order we are not, of course, aware; but it reads something like a reflection on the rapacity of Medical Officers, or the extravagance and folly of Native Princes;--one, or other, or both. It is, we need hardly remark, entirely within the right of Goverument to lend the services of its officers to the public in general or to Native Princes; but the policy of Government as regards the terms on which such services are given and accepted has hitherto been to leave these to be adjusted privately by the persons concerned. Even in the case of attendance on the wives and children of those Officers of Government who are not entitled to claim the services of Medical Officers for their families, Government has always been very averse to it terfere, and, in most cases, these matters are amicably and equitably arranged. This order, therefore, constitutes a new departure and we cannot but regret extremely that its issue should have been found necessary. We are not prepared to assert that the interference of Government may not be necessary in some cases of the nature indicated in the order, but we incline to think that these are very exceptional; and it appears to us to be a preferable course to deal with such cases specially and exceptionally, rather than subject a whole Service to a degradation,-for the imputation of extortion which the order implies is degrading. We are not in favour of medical men charging or accepting excessive or fancy fees or doing any act which has the remotest semblance of putting on the screw; still, the remuneration of medical services is a very elastic thing, depending on a multitude of circumstances, among which the rank, wealth, and position of the patient, the skill of the attendant, the amount of time and labour consumed, and distance travelled, are important elements. Besides, who is the best judge of the value of pain relieved, disability removed, life saved? We should say the patient ; and it seems hardly right to place bounds on his sense of relief and gratitude. As a matter of fact, lawyers receive much larger fees from Native Princes and wealthy people in this country than doctors; and it should not be forgotten that the services of its medical officers have been, on many occasions, of immense political value to Government. While regretting that the issue of this order should have been considered necessary, we hope that it will be carried out with delicacy and liberality.

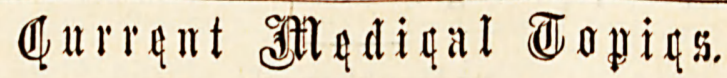

A TEXT.BOOK OF MEDICAL JURISPRUDENCE FOR INDIA.

Through the conrtesy of the publishers, Messrs. 'Thacker, Spink \& Co., we have 